\title{
New advances in the genetics of early onset obesity
}

\author{
International Journal of Obesity (2005) 29, 1149-1152. doi:10.1038/sj.ijo.0803056
}

\section{Genes vs environment}

The rising prevalence of childhood obesity is largely driven by recent changes in diet and levels of physical activity; however, there is strong evidence to suggest that like height, weight is a highly heritable trait (40-70\% heritability). ${ }^{1,2}$ It is very likely that the ability to store fat in times of nutritional abundance was a positive trait selected over thousands of years of evolution only to emerge recently on a large scale as a result of changes in our environment. There is increasing recognition that studies aimed at identifying these polygenic or oligogenic influences on weight gain in childhood are needed and a number of loci have been identified in genome-wide scans in different populations, although as yet few have been replicated. ${ }^{3,4}$

As well as a detectable shift in the mean BMI of children and adults in most populations, we are seeing a greater proportion of patients of all ages with severe obesity. It is clear that these individuals have a certain genetic propensity to store excessive caloric intake as fat and it is important to have a practical approach to the investigation and management of these vulnerable patients who have considerably increased morbidity and mortality. Although there is no accepted definition for severe or morbid obesity in childhood, a BMI s.d. $>2.5$ (weight off the chart) is often used in Specialist Centres and the crossing of major growth percentile lines upward is an early indication of risk of severe obesity.

\section{Diagnostic approach}

The assessment of severely obese children and adults should be directed at screening for potentially treatable endocrine and neurological conditions and identifying genetic conditions so that appropriate genetic counselling and in some cases treatment can be instituted. Much of the information needed can be obtained from a careful medical history and physical examination (Table 1), which should also address the potential complications of severe obesity. ${ }^{5}$ The presence of hyperphagia and obesity in a young child $(<5 \mathrm{y})$ and a positive family history of early-onset obesity support a genetic diagnosis.

Classically, patients affected by genetic obesity syndromes have been identified as a result of their association with developmental delay, dysmorphic features and/or other developmental abnormalities. More recently, several single gene disorders resulting from disruption of the hypothalamic leptin-melanocortin signalling pathway have been identified. In these disorders, obesity itself is the predominant presenting feature, although frequently accompanied by characteristic patterns of neuroendocrine dysfunction, which will only become apparent on investigation (Table 2). For the purposes of clinical assessment, it remains useful to categorize the genetic obesity syndromes as those with dysmorphism and/or developmental delay and those without these features.

\section{Advances in the understanding of dysmorphic obesity syndromes}

There are about 30 Mendelian disorders with obesity as a clinical feature but often associated with mental retardation, dysmorphic features and organ-specific developmental abnormalities (ie pleiotropic syndromes) (for a complete list see Farooqi and $\mathrm{O}^{\prime} \mathrm{Rahilly}^{6}$ ). There have been major advances in our understanding of the molecular basis for a number of these complex obesity syndromes, such as Bardet-Beidl syndrome (BBS), which is a rare genetically heterogeneous autosomal recessive syndrome characterized by central obesity, mental retardation, dysmorphic extremities, retinal dystrophy/pigmentary retinopathy, hypogonadism and renal abnormalities. Recently, phylogenetic/genomic approaches have led to the identification of a number of new BBS genes, which have been implicated in the generation of both cilia and flagella in a cell- and developmental stagespecific manner, and thus led to the identification of novel molecular mechanisms underlying this disorder. ${ }^{7,8}$ Mutations in the neurotrophin receptor TrkB and potentially in its ligand BDNF cause severe hyperphagia and obesity, delayed speech and language, impaired short-term memory and impaired nociception. ${ }^{9}$

\section{Advances in the understanding of nondysmorphic obesity syndromes}

We and others have identified five monogenic obesity syndromes where obesity in early childhood is the presenting feature in children who are developmentally normal with no dysmorphism. To date, all these disorders involve 
History

- Age of onset - early onset ( $<5 y$ of age) suggests a genetic cause.

- Duration of obesity - short history suggests endocrine or central cause.

- Frequent infections and fatigue may suggest ACTH deficiency due to POMC mutations.

- Hyperphagia - often denied but sympathetic approach needed and specific questions, such as waking at night to eat, demanding food very soon after a meal suggest hyperphagia. If severe, especially in children, suggests a genetic cause for obesity.

- Developmental delay - milestones, educational history, behavioural disorders. Consider craniopharyngeoma or structural causes (often relatively short history) and genetic causes.

- Visual impairment and deafness can suggest genetic causes.

- Onset and tempo of pubertal development - onset can be early or delayed in children and adolescents. Primary hypogonadotropic hypogonadism or hypogenitalism associated with some genetic disorders.

- Family history - consanguineous relationships, other children affected and family photographs useful. Severity may differ due to environmental effects.

Table 2 Obesity syndromes

\begin{tabular}{|c|c|}
\hline Syndrome & Additional clinical features \\
\hline \multicolumn{2}{|l|}{ Developmental delay/dysmorphism } \\
\hline Prader-Willi syndrome & Hypotonia, difficulty feeding followed by hyperphagia, short stature, hypogonadotropic hypogonadism \\
\hline Fragile $\mathrm{X}$ syndrome & Hyperkinetic behaviour, macro-orchidism, large ears, prominent jaw and high-pitched jocular speech \\
\hline BBS & $\begin{array}{l}\text { Dysmorphic extremities, retinal dystrophy or pigmentary retinopathy, hypogonadism and structural abnormalities } \\
\text { of the kidney or functional renal impairment }\end{array}$ \\
\hline Cohen syndrome & Prominent central incisors, opthalmopathy, microcephaly \\
\hline Albright's hereditary osteodystrophy & $\begin{array}{l}\text { Short stature, brachydactyly and ectopic soft-tissue ossification plus resistance to several hormones } \\
\text { (eg parathyroid hormone) }\end{array}$ \\
\hline Wilson-Turner syndrome & Tapering fingers, gynaecomastia \\
\hline Borjeson-Forssman-Lehmann syndrome & Hypogonadism, large ears, gynaecomastia \\
\hline TrkB deficiency & Severe hyperphagia, impaired speech and language, impaired nociception \\
\hline \multicolumn{2}{|l|}{ Normal development/no dysmorphism } \\
\hline Alstrom syndrome & Retinal dystrophy, neurosensory deafness, diabetes \\
\hline Ulnar-mammary syndrome & Ulnar defects, delayed puberty, hypoplastic nipples \\
\hline Leptin deficiency & Central hypothyroidism, hypogonadotropic hypogonadism, excessive body fat, frequent infections \\
\hline Leptin receptor deficiency & Central hypothyroidism, hypogonadotropic hypogonadism, excessive body fat \\
\hline POMC deficiency & ACTH deficiency, red hair and pale skin in Caucasians, mild central hypothyroidism \\
\hline PC-1 deficiency & Neonatal diarrhoea, recurrent hypoglycaemia, global endocrine dysfunction \\
\hline MC4R deficiency & Increased linear growth and increased lean mass, severe hypersinsulinaemia, mild central hypothyroidism \\
\hline
\end{tabular}

the leptin-melanocortin axis, which has been extensively studied in rodents and has provided the framework for the identification of these disorders in humans. ${ }^{10}$ We know that the hypothalamus receives inputs from long-term signals of adipose tissue stores, in particular leptin and insulin and short-term, meal-related signals from the gut (PYY, GLP-1, CCK and ghrelin). ${ }^{11}$ Leptin stimulates the expression of POMC, which is cleaved by prohormone convertases to yield the melanocortin peptides, which act as suppressors of feeding through the melanocortin 4 receptor (MC4R). Targeted disruption of MC4R in rodents leads to increased food intake, obesity, severe early hyperinsulinaemia and increased linear growth. ${ }^{12}$

\section{Congenital leptin and leptin receptor deficiency}

Congenital leptin deficiency is characterized by severe hyperphagia from 4 months of age. ${ }^{13}$ The disabling obesity of leptin deficiency is characterized by the selective deposition of fat and children often develop valgus deformities of the knees by the age of 5-6y, sleep apnoea and high rates of childhood infection and atopic disease due to abnormalities of T-cell number and function. ${ }^{14}$ Hypothalamic hypothyroidism is seen at a young age with a subsequent failure to undergo pubertal development due to hypogonadotropic hypogonadism. Mutations in the leptin receptor result in a comparable phenotype, ${ }^{15}$ although are not necessarily associated with elevated serum leptin concentrations (personal communication). Although leptin deficiency appears to be rare, it is entirely treatable with daily subcutaneous injections of recombinant human leptin with beneficial effects on appetite, fat mass and hyperinsulinaemia, reversal of the immune defects and infection risk and allowing the appropriate development of puberty ${ }^{14}$ (Figure 1). Such treatment represents the first, rationally based, hormone replacement therapy for any form of human obesity. Thus, measurement of serum leptin is useful in severely obese 

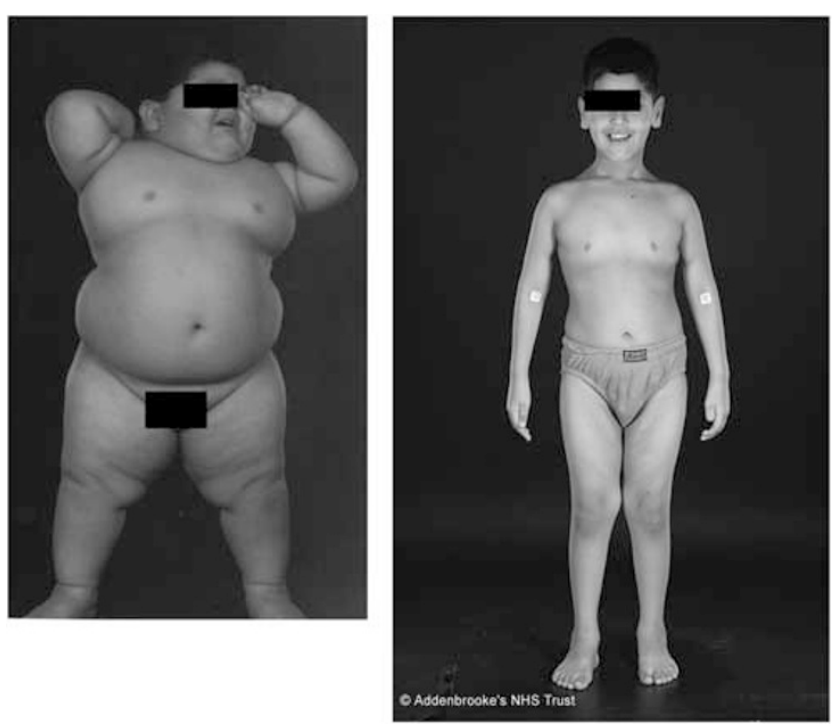

Figure 1 Response to leptin therapy in a child with leptin deficiency.

children, particularly in consanguinous families as congenital leptin deficiency is recessively inherited.

\section{POMC and POMC processing deficiency}

Children who are homozygous or compound heterozygous for mutations in the POMC (pro-opiomelanocortin) gene present in neonatal life with adrenal crisis due to ACTH deficiency (POMC is a precursor of ACTH in the pituitary) and require long-term corticosteroid replacement. ${ }^{16}$ Such children have pale skin and red hair due to the lack of MSH function at melanocortin 1 receptors in the skin, although this may be less obvious in children from different ethnic backgrounds (personal communication). POMC deficiency results in hyperphagia and early-onset obesity due to loss of melanocortin signalling at the MC4R. Although as yet trials of treatment have not been performed, it is plausible that selective MC4R agonists will be available for such patients in the near future. Prohormone convertase 1 is involved in the processing of POMC and other neuropeptides and mutations in this gene cause small bowel enteropathy and complex neuroendocrine effects due to a failure to process a number of prohormones. $^{17}$

\section{MC4R deficiency}

MC4R deficiency is a dominantly inherited obesity syndrome which was first described in $1998 .{ }^{18}$ Since that time many different heterozygous MC4R mutations have been reported in obese people from various ethnic groups. The prevalence of such mutations has varied from $0.5 \%$ of obese adults to $6 \%$ in subjects with severe childhood obesity. ${ }^{19}$ Recent studies in the Danish population ${ }^{20}$ provide an important indication of the true population prevalence of this disorder. Pederson and colleagues showed that $2.5 \%$ of people with a $\mathrm{BMI}>30 \mathrm{~kg} / \mathrm{m}^{2}$ had a pathogenic mutation in MC4R, confirming that MC4R deficiency is the most common obesity syndrome described to date and is one of the most common genetic diseases with a predicted prevalence comparable to diseases such as cystic fibrosis.

The clinical features of MC4R deficiency include hyperphagia, which invariably starts in the first year of life. ${ }^{19}$ Alongside the increase in fat mass, MC4R-deficient subjects also have an increase in lean mass and a marked increase in bone mineral density, thus they often appear 'big-boned'. They exhibit accelerated linear growth in early childhood, which does not appear to be due to dysfunction of the $\mathrm{GH}$ axis and may be a consequence of the disproportionate early hyperinsulinaemia seen in these patients. Of particular note is the finding that the severity of receptor dysfunction seen in vitro assays can predict the amount of food ingested at a test meal by the subject harbouring that particular mutation. ${ }^{19}$

While, at present, there is no specific therapy for MC4R deficiency, it is highly likely that these subjects would respond well to pharmacotherapy that overcame the reduction in the hypothalamic melanocortinergic tone that exists in these patients. As most patients are heterozygotes with one functional allele intact, it is possible that small molecule MC4R agonists might, in future, be excellent treatments for this disorder.

\section{Conclusions}

Although some monogenic syndromes are rare, an improved understanding of the precise nature of the inherited component of severe obesity has undoubted medical benefits and helps to dispel the notion that obesity represents an individual defect in behaviour with no biological basis. The practical implications of these findings for genetic counselling and even therapy have already been realized and given the rapid pace of genetic and molecular technologies, it is very likely that new genes, proteins and mechanisms will emerge to explain a variety of previously unrecognized obesity syndromes in the near future.

We predict that the effective clinical evaluation of the severely obese child will become increasingly sophisticated and require the development of expertise in the recognition of these emerging syndromes together with the incorporation of novel biochemical and molecular genetic diagnostics. These approaches will need to be combined with the more traditional nutritional and behavioural approaches to optimize treatment for individual children.

\section{Acknowledgements}

We thank all the physicians who have referred and continue to refer patients with severe childhood obesity to our Genetics of Obesity Study (GOOS) and without whose 
support this work could not have taken place. This work was funded by the Wellcome Trust and MRC.

IS Farooqi ${ }^{1}$ and S O'Rahilly ${ }^{1}$

${ }^{1}$ Wellcome Clinician Scientist Fellow, University Departments of Medicine and Clinical Biochemistry, Addenbrooke's Hospital, Cambridge, UK

\section{References}

1 Barsh GS, Farooqi IS, O'Rahilly S. Genetics of body-weight regulation. Nature 2000; 404: 644-651.

2 Maes HH, Neale MC, Eaves LJ. Genetic and environmental factors in relative body weight and human adiposity. Behav Genet 1997; 27: 325-351.

3 Meyre D, Lecoeur C, Delplanque J, Francke S, Vatin V, Durand E, Weill J, Dina C, Froguel P. A genome-wide scan for childhood obesity-associated traits in French families shows significant linkage on chromosome 6q22.31-q23.2. Diabetes 2004; 53: 803-811.

4 Perusse L, Rankinen T, Zuberi A, Chagnon YC, Weisnagel SJ, Argyropoulos G, Walts B, Snyder EE, Bouchard C. The human obesity gene map: the 2004 update. Obes Res 2005; 13: 381-490.

5 Dietz WH, Robinson TN. Clinical practice-overweight children and adults. N Engl J Med 2005; 352: 2100-2109.

6 Farooqi IS, O'Rahilly S. Monogenic obesity in humans. Annu Rev Med 2005; 56: 443-458.

7 Mykytyn K, Sheffield VC. Establishing a connection between cilia and Bardet-Biedl syndrome. Trends Mol Med 2004; 10: 106-109.

8 Beales PL. Lifting the lid on Pandora's box: the Bardet-Biedl syndrome. Curr Opin Genet Dev 2005; 15: 315-323.

9 Yeo GS, Connie Hung CC, Rochford J, Keogh J, Gray J, Sivaramakrishnan S, O'Rahilly S, Farooqi IS. A de novo mutation affecting human TrkB associated with severe obesity and developmental delay. Nat Neurosci 2004; 7: 1187-1189.

10 Schwartz MW, Woods SC, Porte Jr D, Seeley RJ, Baskin DG. Central nervous system control of food intake. Nature 2000; 404: 661-671.
11 Cummings DE, Schwartz MW. Genetics and pathophysiology of human obesity. Annu Rev Med 2003; 54: 453-471.

12 O'Rahilly S, Yeo GS, Farooqi IS. Melanocortin receptors weigh in. Nat Med 2004; 10: 351-352.

13 Montague CT, Farooqi IS, Whitehead JP, Soos MA, Rau $\mathrm{H}$ Wareham NJ, Sewter CP, Digby JE, Mohammed SN, Hurst JA, Cheetham CH, Earley AR, Barnett AH, Prins JB, O'Rahilly S. Congenital leptin deficiency is associated with severe early-onset obesity in humans. Nature 1997; 387: 903-908.

14 Farooqi IS, Matarese G, Lord GM, Keogh JM, Lawrence E, Agwu C, Sanna V, Jebb SA, Perna F, Fontana S, Lechler RI, DePaoli AM, O'Rahilly S. Beneficial effects of leptin on obesity, $\mathrm{T}$ cell hyporesponsiveness, and neuroendocrine/metabolic dysfunction of human congenital leptin deficiency. J Clin Invest 2002; 110: 1093-1103.

15 Clement K, Vaisse C, Lahlou N, Cabrol S, Pelloux V, Cassuto D, Gourmelen M, Dina C, Chambaz J, Lacorte JM, Basdevant A, Bougneres P, Lebouc Y, Froguel P, Guy-Grand B. A mutation in the human leptin receptor gene causes obesity and pituitary dysfunction. Nature 1998; 392: 398-401.

16 Krude H, Biebermann H, Luck W, Horn R, Brabant G, Gruters A. Severe early-onset obesity, adrenal insufficiency and red hair pigmentation caused by POMC mutations in humans. Nat Genet 1998; 19: 155-157.

17 Jackson RS, Creemers JW, Farooqi IS, Raffin-Sanson ML, Varro A, Dockray GJ, Holst JJ, Brubaker PL, Corvol P, Polonsky KS, Ostrega D, Becker KL, Bertagna X, Hutton JC, White A, Dattani MT, Hussain K, Middleton SJ, Nicole TM, Milla PJ, Lindley KJ, O'Rahilly S. Small-intestinal dysfunction accompanies the complex endocrinopathy of human proprotein convertase 1 deficiency. J Clin Invest 2003; 112: 1550-1560.

18 Yeo GS, Farooqi IS, Aminian S, Halsall DJ, Stanhope RG, O’Rahilly S. A frameshift mutation in MC4R associated with dominantly inherited human obesity. Nat Genet 1998; 20: 111-112.

19 Farooqi IS, Keogh JM, Yeo GS, Lank EJ, Cheetham T, O'Rahilly S. Clinical spectrum of obesity and mutations in the melanocortin 4 receptor gene. N Engl J Med 2003; 348: 1085-1095.

20 Larsen LH, Echwald SM, Sorensen TI, Andersen T, Wulff BS, Pedersen O. Prevalence of mutations and functional analyses of melanocortin 4 receptor variants identified among 750 men with juvenile-onset obesity. J Clin Endocrinol Metab 2005; 90: 219-224. 